\title{
An Investigation on self-polymerization and co-polymerization properties of lead methacrylate
}

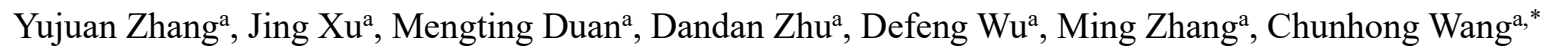 \\ ${ }^{a}$ School of Chemistry and Chemical Engineering, Yangzhou University, Yangzhou 225002, China \\ *Corresponding Author: wangch@yzu.edu.cn
}

\begin{abstract}
Lead methacrylate $\left(\mathrm{Pb}(\mathrm{MAA})_{2}\right)$ was synthesized through the reaction of lead oxide and methacrylic acid and characterized by FT-IR spectroscopy, XRD, DSC. The non-isothermal and isothermal analysis were used to study the kinetics of self-polymerization of $\mathrm{Pb}(\mathrm{MAA})_{2}$. The monomer reactivity ratios of $\mathrm{Pb}(\mathrm{MMA})_{2} / \mathrm{MMA}$, $\mathrm{Pb}(\mathrm{MAA})_{2} / \mathrm{St}$ and $\mathrm{Pb}(\mathrm{MAA})_{2} / \mathrm{BA}$ were calculated by K-T method. The results showed that $\mathrm{Pb}(\mathrm{MMA})_{2}$ could be induced to self-polymerization initiated by thermal and free radical and the activation energy of polymerization was $150.10 \mathrm{~kJ} / \mathrm{mol}$ in solid state and $74.99 \mathrm{~kJ} / \mathrm{mol}$ in aqueous solution. The rate of polymerization under low conversion was governed by the expression at $70^{\circ} \mathrm{C}: \mathrm{Rp}=\mathrm{K}[\mathrm{M}]^{1.02}[\mathrm{I}]^{0.37}$. The values of $r_{1}\left(\mathrm{~Pb}(\mathrm{MAA})_{2}\right)$ and $\mathrm{r}_{2}(\mathrm{MMA})$ were 3.767 and $0.166, \mathrm{r}_{1}\left(\mathrm{~Pb}(\mathrm{MAA})_{2}\right)$ and $\mathrm{r}_{2}(\mathrm{St})$ were 26.856 and $0.294, \mathrm{r}_{1}$ $\left(\mathrm{Pb}(\mathrm{MAA})_{2}\right)$ and $\mathrm{r}_{2}(\mathrm{BA})$ were 10.822 and 0.089 .
\end{abstract}

Keywords: lead methacrylate; thermal analysis; kinetics of the polymerization; monomer ratios.

\section{Introduction}

It is well known that lead plates are an effective anti-X-ray shielding material, but they has poor structural properties, and large, opaque and inconvenient to use $\mathrm{e}^{(1)}$. Polymer organic radiation protection materials has been received more and more attention because of their simple preparation method, good performance, small specific gravity and low price ${ }^{(2)}$.

Generally mental elements can be induced into the polymer matrix by physical blending or chemical attachment ${ }^{(3)}$. Physical blending is a simple way to produce mental-containing polymer, but most mental compounds have a bad compatibility with polymer and uneven dispersion which will cause poor mechanical properties. The chemical attachment method consists of two parts: ( I ) the interaction of mental ion with linear functionalized(such as carboxyl-containing) polymers; (II) the polymerization and copolymerization of mental monomers.

The advantage of Method (II) is that high mental content can be get and easy to quantify. The lead monomer had been synthesized (4-5), but until now no papers have studied the self-polymerization and co-polymerization properties of the lead monomer.

In this paper, lead methacrylate $\left(\mathrm{Pb}(\mathrm{MAA})_{2}\right)$ as an example of mental monomers was synthesized and its polymerization kinetics was studied through the thermal analysis. The reactivity ratio of $\mathrm{Pb}(\mathrm{MAA})_{2}$ and methyl methacrylate/ styrene/ N-butyl acrylate were investigated and calculated by K-T method.

\section{Experimentation}

\subsection{Materials}

Lead oxide (PbO, AR), methacrylic acid (MAA, CP), ethanol (AR), N,N-dimethylformamide (DMF,AR), methyl methacrylate (MMA, CP), styrene(St, AR) , N-butyl acrylate (BA, AR), azodiisobutyronitrile (AIBN, CP) were obtained from Sinpharm Chemical Reagent Co., Ltd. MMA, St, BA were washed by sodium hydroxide solution and distilled water to eliminate the inhibitor and AIBN was recrystallization before used.

\subsection{Synthesis of lead methacrylate $\left(\operatorname{Pb}(\mathrm{MAA})_{2}\right)$}

$\mathrm{Pb}(\mathrm{MAA})_{2}$ was prepared by adding $\mathrm{PbO}, \mathrm{MAA}$ and EtOH with the molar ratio of 1:2.6:2.6 into a $100-\mathrm{mL}$ three-necked flask. The reaction was carried out at $70^{\circ} \mathrm{C}$ for 20min until all the powders had been dissolved and the solution became transparent. The solution was filtered 
while still hot. A white precipitate was obtained by adding a small amount of water while stirring. The solid was filtered off, washed with ethyl alcohol and dried under vacuum. The final product was obtained in about $80 \%$ yield.

\subsection{Polymerization}

Self-polymerization of $\mathrm{Pb}(\mathrm{MAA})_{2}$ was carried out in a $5 \mathrm{ml}$ vessel using DMF as a reaction medium and AIBN as a initiator and the exothermic process of polymerization was directly detected by the micre-DSC.

Copolymerization of $\mathrm{Pb}(\mathrm{MAA})_{2}$ and $\mathrm{MMA} / \mathrm{St} / \mathrm{BA}$ were carried out in a three-necked flask at $70^{\circ} \mathrm{C}$ under nitrogen atmosphere using DMF as a reaction medium and AIBN as a initiator respectively. In the reaction system, the total monomer concentration was $20 \mathrm{wt} \%$, and the initiator concentration was $5 \mathrm{wt} \%$ (on the basis of total monomers). Good agitation was used in the polymerization process to throw off the reaction heat instantaneously. The copolymerization was terminated at a low conversion of $\leq 10 \%$ to keep the copolymerization at a steady reaction stage. Then the precipitate mixture was isolated by filtration, washed successively with water and ethyl alcohol, and dried under vacuum at $60^{\circ} \mathrm{C}$. The low conversions were measured by weighing method.

\subsection{Characterizations}

XRD pattern was obtained on a Bruker-AXS X-ray equipped with graphite monochromator and $\mathrm{CuKa}$ radiation $(\lambda=1.5406 \AA)$. The Fourier transform infrared (FT-IR) spectra of samples were recorded at a resolution of $1 \mathrm{~cm}^{-1}$ on a Varian Cary 5000 spectrometer. The thermal characteristics of $\mathrm{Pb}(\mathrm{MAA})_{2}$ was obtained by DSC (PerkinElmer, DSC 8500). The analyses were performed at a heating rate of $10^{\circ} \mathrm{C} / \mathrm{min}$ in nitrogen atmosphere.

Non-isothermal analysis by DSC (PerkinElmer, DSC 8500) was used as an alternative way of calculating the self-polymerization activation energy of $\mathrm{Pb}(\mathrm{MAA})_{2}$ in the solid state known as the Kissinger method ${ }^{(6)}$. Kissinger method is based on a linear relationship between the $\operatorname{logarithm~} \beta / \mathrm{Tp}^{2}$ with the inverse of the endothermic peak through the following expression:

$$
\ln \left[\frac{\beta}{\mathrm{T}_{\mathrm{p} 2}}\right]=\ln \left[\frac{\mathrm{RA}}{\mathrm{E}}\right]-\frac{\mathrm{E}}{\mathrm{RT}_{\mathrm{p}}}
$$

where $\beta$ is the heating $\operatorname{rate}\left({ }^{\circ} \mathrm{C} / \mathrm{K}\right), \mathrm{Tp}$ is the endothermic peak temperature $(\mathrm{K}), \mathrm{R}$ is ideal gas constant.

Isothermal analysis by micro-DSC (Setaram, C80 ) was used to study the kinetics of the radical polymerization of $\mathrm{Pb}(\mathrm{MAA})_{2}$ in aqueous solution using ammonium persulphate as initiator. With the presumption that the heat flow, $\mathrm{dH} / \mathrm{dt}$, was proportional to the rate of reaction $\mathrm{d} \alpha / \mathrm{dt}$, it is possible to determine the extent of conversion, $\alpha$, directly from the experimental curve by partial intergration (7):

$$
\alpha=\frac{1}{\Delta \mathrm{H}_{\mathrm{T}}} \int_{\mathrm{o}}^{\mathrm{t}} \frac{\mathrm{dH}}{\mathrm{dt}} \mathrm{dt}
$$

where $\Delta \mathrm{H}_{\mathrm{T}}$ stands for the total heat of polymerization. The dependence of polymerization rate on initiator and concentration was determined by varying concentration of one species while keeping the other constant and vice versa. The effect of temperature on the conversion was investigated at constant monmer and initiator concentrations.

Element analysis method was used to calculate monomer reactivity ratios of $\mathrm{Pb}(\mathrm{MAA})_{2} / \mathrm{MMA}$, $\mathrm{Pb}(\mathrm{MAA})_{2} / \mathrm{St}$ and $\mathrm{Pb}(\mathrm{MAA})_{2} / \mathrm{BA}$. The lead $(\mathrm{Pb})$ contents of the copolymer were obtained by ash determination method.

\section{Results and discussion}

From the XRD spectra as shown in fig.1, the characteristic diffraction peaks in $\mathrm{PbO}$ are disappeared in $\mathrm{Pb}(\mathrm{MAA})_{2}$ which means the synthetic reaction of $\mathrm{Pb}(\mathrm{MAA})_{2}$ is sufficient and the product is pure. The intensity diffraction peaks at $7.6^{\circ}$ in $\mathrm{Pb}(\mathrm{MAA})_{2}$ reveal the product is highly crystalline.

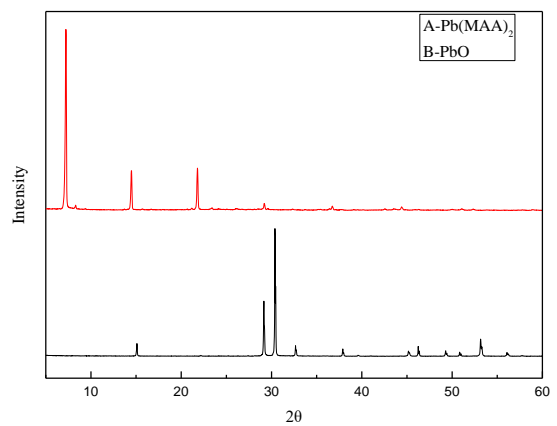

Fig. 1 XRD spectra of (A) $\mathrm{Pb}(\mathrm{MAA})_{2}$; (B) $\mathrm{PbO}$

Fig.2 shows the FT-IR spectra of MAA and $\mathrm{Pb}(\mathrm{MAA})_{2}$. The bands characteristic of the nonionized carboxyl groups $v(\mathrm{C}=\mathrm{O})$ that lies in the interval $1690-1710$ $\mathrm{cm}^{-1}$ in fig.2B disappear and new bands appeare in the regions $1520-1580 \mathrm{~cm}^{-1}$ and $1395-1430 \mathrm{~cm}^{-1}$ respectively which belong to the stretching vibrationsvas(COO-) and vs(COO-) of carboxylate ion in fig.2A. It means the lead ion and carboxyl groups have coordination reaction with each other. The frequencies of stretching vibrations $v(C=C)$ does not change significantly between MAA and 
$\mathrm{Pb}(\mathrm{MAA})_{2}$, that signify $\mathrm{Pb}(\mathrm{MAA})_{2}$ had the ability of polymerization.

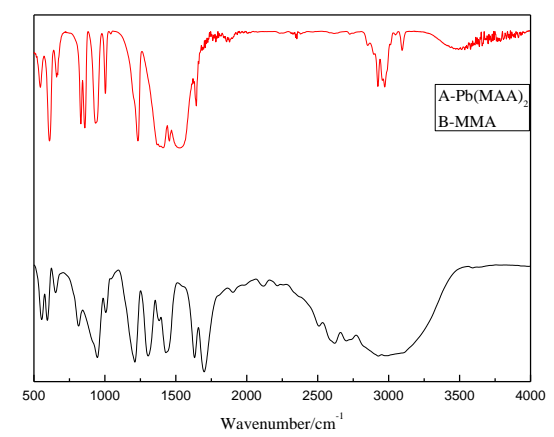

Fig.2 FT-IR spectra of (A) Pb(MAA) 2 ; (B) MAA

In order to confirm the polymerization ability of $\mathrm{Pb}(\mathrm{MAA})_{2}$, the thermal analysis is taken as showed in fig. 3 . one sharp endothermic peaks at $74.39^{\circ} \mathrm{C}$ in fig. 3 can be related to the melting of $\mathrm{Pb}(\mathrm{MAA})_{2}$ crystals $^{(8)}$. There is a significant exothermic peak at $220-273^{\circ} \mathrm{C}$ in fig. 3 .

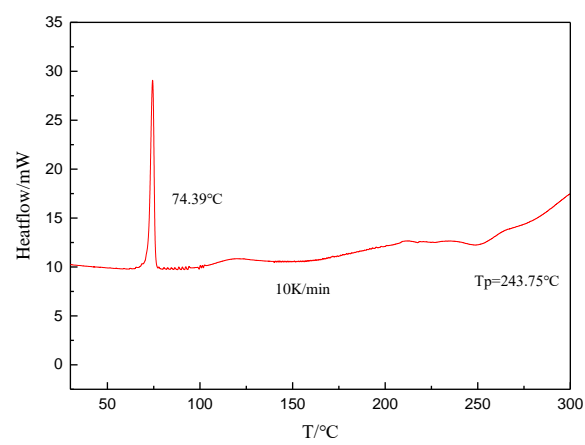

Fig. 3 DSC curves of $\mathrm{Pb}(\mathrm{MAA})_{2}$ at $10^{\circ} \mathrm{C} / \mathrm{min}$

It has confirmed that $\mathrm{Pb}(\mathrm{MAA})_{2}$ can be induced self-polymerization initiated by thermal at $220-273^{\circ} \mathrm{C}$ from above analysis. As shown in fig.4, Tp is raised from 241.7 to $261.57^{\circ} \mathrm{C}$ along with the heating rate from 5 to $20^{\circ} \mathrm{C} / \mathrm{min}$ and the activation energy (Ea) of polymerization is $150.10 \mathrm{~kJ} / \mathrm{mol}$ calculated by Eq (1).

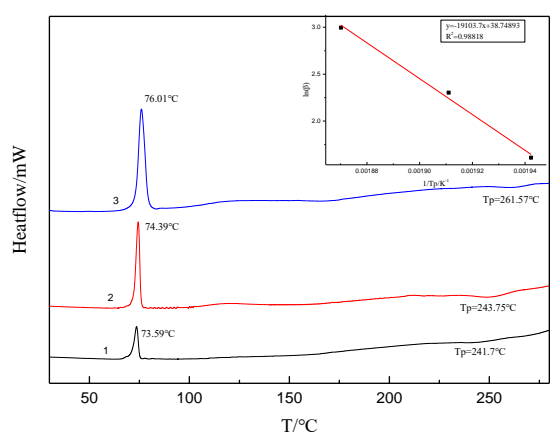

Fig. $4 \mathrm{DSC}$ curves of $\mathrm{Pb}(\mathrm{MAA})_{2}$ at different heating rates:(1) 5 ;(2) 10 ;(3) $20^{\circ} \mathrm{C} / \mathrm{min}$.Inset: Kissinger method plot for activation energy determination of $\mathrm{Pb}(\mathrm{MAA})_{2}$.
Most of previous workers used the dilatometer and gravimetry technique to study the radical chain polymerization (9-10). Here isothermal analysis by micro-DSC is used to study the kinetics of the radical polymerization of $\mathrm{Pb}(\mathrm{MAA})_{2}$ in aqueous solution. The conversion-time curves are generally $\mathrm{S}$-shaped as shown in fig.5. At the very beginning of the polymerization, conversion and time are appeared approximate linear relationship. As the reaction going, the poly $\left(\mathrm{Pb}(\mathrm{MAA})_{2}\right)$ is precipitated from the solution that cause the gel effect and increase the polymerization rate rapidly. Generally the dependence of polymerization rate on monomer and initiator concentrations is a important part of the kinetic study. The polymerization rate, $\mathrm{Rp}$, is obtained from the slope of the conversion versus time curve. The relationship of $\mathrm{Rp}$ with monomer and initiator concentration is obtained by plotting the $\ln [\mathrm{Rp}]$ versus $\ln [\mathrm{M}]$ and $\ln [\mathrm{I}]$, and the form $\mathrm{Rp} \propto[\mathrm{M}]^{1.02} \times[\mathrm{I}]^{0.37}$ is obtained from the line of the slope as shown in fig.6. The polymerization kinetics equation of $\mathrm{Pb}(\mathrm{MAA})_{2}$ is quite consistent with the classical kinetic theory. The effect of temperature on polymerization rate is shown in fig.7. As the temperature increased, the rate of production of primary free radicals increased, thus increasing the polymerization rate (11). The activation energy is $74.99 \mathrm{~kJ} / \mathrm{mol}$ determined by plotting $\ln [\mathrm{Rp}]$ versus $1 / T(K)$. This value corresponds well with the typical activation energies of propagation in free radical polymerization ${ }^{(12)}$ and it reveal that $\mathrm{Pb}(\mathrm{MAA})_{2}$ was easier to polymerization in solution state than in solid state.
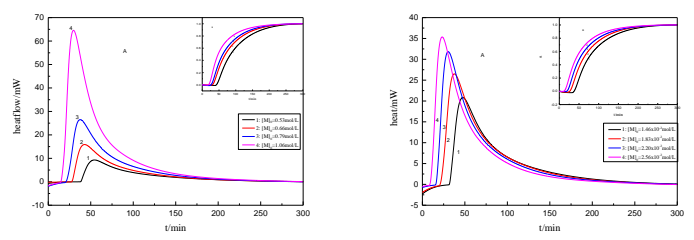

Fig. 5 micro-DSC curves recorded for the polymerization of $\mathrm{Pb}(\mathrm{MAA})_{2}$. Inset: polymerization conversion of $\mathrm{Pb}(\mathrm{MAA})_{2}$ as a function of time. $\mathrm{A}:[\mathrm{M}]_{0}=0.53-1.06 \mathrm{~mol} / 1$, $[\mathrm{I}]=1.83 \times 10^{-2} \mathrm{~mol} / 1$ and $\mathrm{T}=55^{\circ} \mathrm{C} \mathrm{B}$ :

$[\mathrm{I}]=1.46 \times 10^{-2} .56 \times 10^{-2} \mathrm{~mol} / 1,[\mathrm{M}]_{0}=0.66 \mathrm{~mol} / 1$ and $\mathrm{T}=55^{\circ} \mathrm{C}$ 

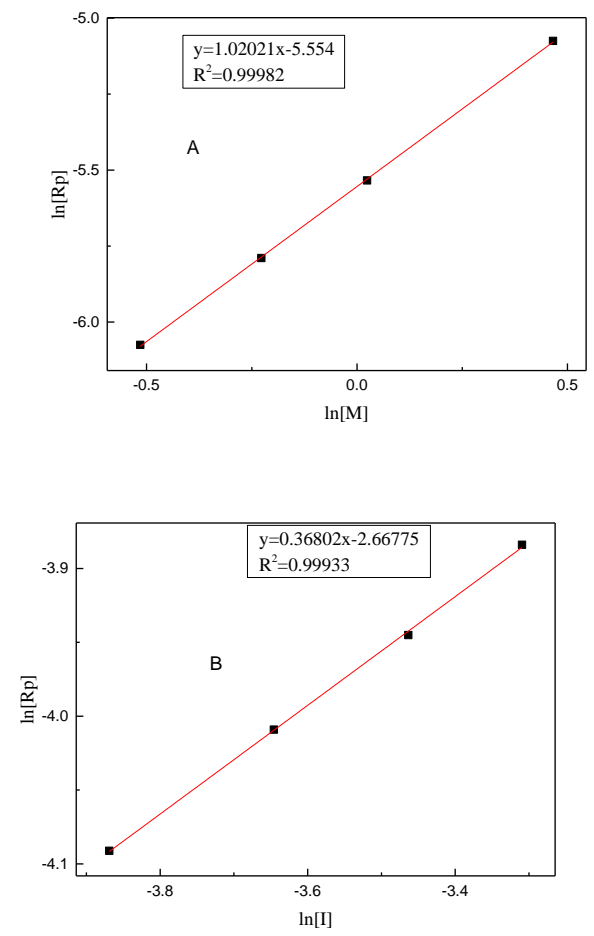

Fig.6 the dependence of Rp [M] (A) and [I] (B) under low conversion
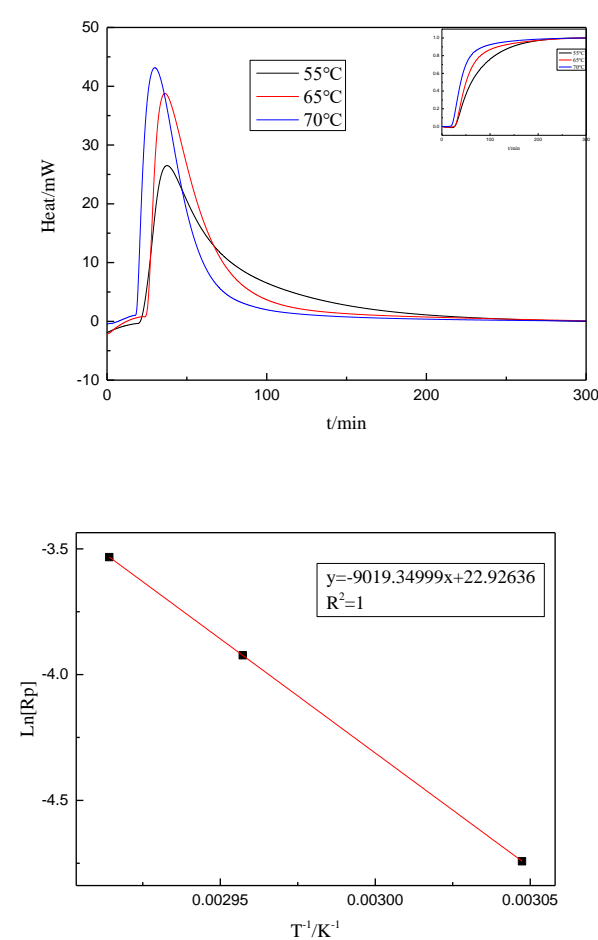

Fig.7 Polymerization conversion of $\mathrm{Pb}(\mathrm{MAA})_{2}$ as a function of time. $\mathrm{T}=55-70^{\circ} \mathrm{C}, \quad[\mathrm{M}]_{0}=0.66 \mathrm{~mol} / 1$,

$[\mathrm{I}]=1.83 \times 10-2 \mathrm{~mol} / 1$.Inset: the dependence of $\mathrm{Rp}$ on $\mathrm{T}$ under low conversion

On the basis of the element analysis results of lead
$\mathrm{Pb}(\mathrm{MAA})_{2} / \mathrm{St}$ and $\mathrm{Pb}(\mathrm{MAA})_{2} / \mathrm{BA}$ can be calculated by $\mathrm{K}-\mathrm{T}$ method ${ }^{(13)}$. Parameters for copolymerization are detailed in Table 1-3. Fig. $8-10$ is the plot of $\tau$ vs. $\varepsilon$ used to calculate the monomer reactivity ratios by $\mathrm{K}-\mathrm{T}$ method. The values of $r_{1}\left(\mathrm{~Pb}(\mathrm{MAA})_{2}\right)$ and $\mathrm{r}_{2}(\mathrm{MMA})$ are 3.767 and $0.166, \mathrm{r}_{1}$ $\left(\mathrm{Pb}(\mathrm{MAA})_{2}\right)$ and $\mathrm{r}_{2}(\mathrm{St})$ were 26.856 and 0.294, $\mathrm{r}_{1}$ $\left(\mathrm{Pb}(\mathrm{MAA})_{2}\right)$ and $\mathrm{r}_{2}(\mathrm{BA})$ were 10.822 and 0.089 . These values of the reactivity ratios imply that both the growing radical $\sim \sim \sim \mathrm{Pb}(\mathrm{MMA})_{2} \cdot$ and $\sim \sim \mathrm{MMA} \cdot / \sim \sim \mathrm{St} \cdot / \sim \sim \mathrm{BA} \cdot$ prefer to combine with the $\mathrm{Pb}(\mathrm{MMA})_{2}$ unit. That may because that the lead ion has a large coordination number and the carboxylic group of $\sim \sim \mathrm{MMA} \cdot / \sim \sim \sim \mathrm{St} \cdot / \sim \sim \sim \mathrm{BA} \cdot$ can supply lone pair electrons to attract the $\mathrm{Pb}(\mathrm{MMA})_{2}$ monomer, so that the growing radicals are more likely to combine with the $\mathrm{Pb}(\mathrm{MMA})_{2}$ unit. As a result, in order to obtain the copolymer with uniform distributed lead ion, adding the $\mathrm{Pb}(\mathrm{MMA})_{2}$ monomer into the solution drop by drop should be better.

Table 1 Parameters for copolymerization of $\mathrm{Pb}(\mathrm{MMA})_{2} / \mathrm{MMA}$

\begin{tabular}{|c|c|c|c|c|c|}
\hline $\begin{array}{c}\mathrm{Pb}(\mathrm{MMA})_{2} / \mathrm{MMA} \\
(\mathrm{w} / \mathrm{w})\end{array}$ & $5 / 95$ & $10 / 90$ & $20 / 80$ & $25 / 75$ & $30 / 70$ \\
\hline $\mathrm{X}(\mathrm{mol} / \mathrm{mol})$ & 0.014 & 0.029 & 0.066 & 0.088 & 0.1132 \\
\hline $\mathrm{Y}(\mathrm{mol} / \mathrm{mol})$ & 0.0629 & 0.172 & 0.354 & 0.471 & 1.3135 \\
\hline $\mathrm{G}=\frac{X(Y-1)}{Y}$ & -0.150 & -0.141 & -0.120 & -0.099 & -0.0854 \\
\hline $\mathrm{H}=\frac{X^{2}}{Y}$ & 0.002 & 0.005 & 0.012 & 0.012 & 0.023 \\
\hline$\tau=\frac{G}{\alpha+F}$ & 0.245 & 0.416 & 0.627 & 0.693 & 0.755 \\
\hline$\varepsilon=\frac{H}{\alpha+H}$ & -16.192 & -11.825 & -6.132 & -4.161 & -2.867 \\
\hline
\end{tabular}

Table 2 Parameters for copolymerization of $\mathrm{Pb}(\mathrm{MMA})_{2} / \mathrm{St}$

\begin{tabular}{|c|c|c|c|c|c|}
\hline $\begin{array}{c}\mathrm{Pb}(\mathrm{MMA})_{2} / \mathrm{St} \\
(\mathrm{w} / \mathrm{w})\end{array}$ & $10 / 90$ & $15 / 85$ & $20 / 80$ & $25 / 75$ & $30 / 70$ \\
\hline $\mathrm{X}(\mathrm{mol} / \mathrm{mol})$ & 0.030 & 0.049 & 0.069 & 0.092 & 0.118 \\
\hline $\mathrm{Y}(\mathrm{mol} / \mathrm{mol})$ & 0.167 & 0.331 & 0.561 & 0.808 & 1.176 \\
\hline $\mathrm{G}=\frac{X(Y-1)}{Y}$ & -0.152 & -0.098 & -0.054 & -0.022 & 0.018 \\
\hline $\mathrm{H}=\frac{X^{2}}{Y}$ & 0.006 & 0.007 & 0.008 & 0.010 & 0.012 \\
$\tau=\frac{G}{\alpha+F}$ & -11.104 & -6.446 & -3.252 & -1.180 & 0.885 \\
\hline$\varepsilon=\frac{H}{\alpha+H}$ & 0.407 & 0.467 & 0.509 & 0.562 & 0.593 \\
\hline
\end{tabular}

$(\mathrm{Pb})$, the reactivity ratios of $\mathrm{Pb}(\mathrm{MMA})_{2} / \mathrm{MMA}$, 
Table 3 Parameters for copolymerization of $\mathrm{Pb}(\mathrm{MMA})_{2} / \mathrm{BA}$

\begin{tabular}{|c|c|c|c|c|}
\hline $\begin{array}{c}\mathrm{Pb}(\mathrm{MMA})_{2} / \mathrm{BA} \\
(\mathrm{w} / \mathrm{w})\end{array}$ & $10 / 90$ & $20 / 80$ & $25 / 75$ & $30 / 70$ \\
\hline $\mathrm{X}(\mathrm{mol} / \mathrm{mol})$ & 0.018 & 0.059 & 0.113 & 0.145 \\
\hline $\mathrm{Y}(\mathrm{mol} / \mathrm{mol})$ & 0.303 & 0.85 & 1.497 & 1.926 \\
\hline $\mathrm{G}=\frac{X(Y-1)}{Y}$ & -0.040 & -0.010 & 0.037 & 0.069 \\
\hline $\mathrm{H}=\frac{X^{2}}{Y}$ & 0.001 & 0.004 & 0.008 & 0.010 \\
\hline$\tau=\frac{G}{\alpha+F}$ & 0.273 & 0.519 & 0.646 & 0.726 \\
\hline$\varepsilon=\frac{H}{\alpha+H}$ & -1.786 & 3.359 & 3.652 & 4.518 \\
\hline
\end{tabular}

Ps: $\alpha=\sqrt{\mathrm{H}_{\min } \times \mathrm{H}_{\max }}$

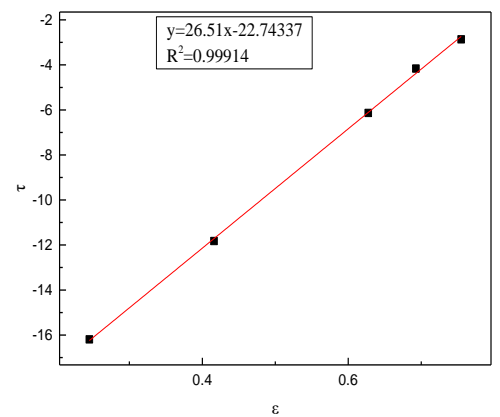

Fig.8 The plot of $\tau$ vs. $\varepsilon$ related to the monomer reactivity ratios of $\mathrm{Pb}(\mathrm{MMA})_{2} / \mathrm{MMA}$ calculated by $\mathrm{K}-\mathrm{T}$ method

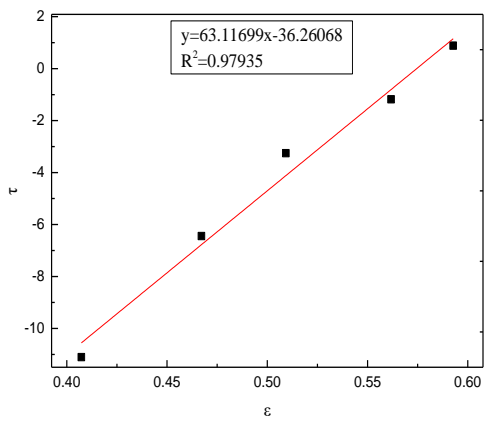

Fig.9 The plot of $\tau$ vs. $\varepsilon$ related to the monomer reactivity ratios of $\mathrm{Pb}(\mathrm{MMA})_{2} / \mathrm{St}$ calculated by K-T method

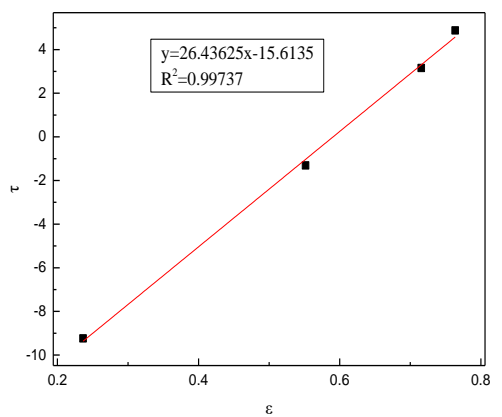

Fig.10 The plot of $\tau$ vs. $\varepsilon$ related to the monomer reactivity ratios of $\mathrm{Pb}(\mathrm{MMA})_{2} / \mathrm{BA}$ calculated by $\mathrm{K}-\mathrm{T}$ method

\section{Conclusions}

In summary, Lead methacrylate as a kind of new monomer can be synthesized through the reaction of lead oxide and methacrylic acid with a quite high yield. As the existence of $\mathrm{C}=\mathrm{C}$ bond, $\mathrm{Pb}(\mathrm{MMA})_{2}$ can be self-polymerization initiated by thermal and free radical. The characteristic of polymerization in aqueous solution under low conversion is quite consistent with the classical kinetic theory. $\mathrm{Pb}(\mathrm{MMA})_{2}$ monomer also shows a quite high reactivity copolymerization with $\mathrm{MMA} / \mathrm{St} / \mathrm{BA}$ by the inferred from the values of monomer reactivity ratios. The purpose of this paper is to add the basic polymerization parameters of the mental monomer and provide a little help to produce a kind of functional mental-containing polymer materials in the coming future.

\section{References}

(1) Rao Baihua, Wang Wenxue. Development of anti-X-ray plexiglass [J]. Plastics Industry, 1989 (06): 5-9.

(2) Jiang Pingping, Shen Fenglei, Yang Chunling, Yin Fushan. Preparation and properties of radiation-proof lead-containing plexiglass [J]. Plastics Industry, 2000 (04): $17-18+36$

(3) Kumar K N, Kang M, Kumar G B, et al. Energy transfer based photoluminescence properties of co-doped (Er 3++ Pr $3+$ ): PEO+ PVP blended polymer composites for photonic applications[J]. Optical Materials, 54: 6-13, 2016.

(4) Zhou Yonglai, Gu Yunzhi, Chen Yuehui. Development of anti-radiation plexiglass [J]. Chemical World, 1982 (08): 231-233. 
(5) Zhang Guimin, Guo Jianmei, Zhou Chengfei, Liu Yuanli. Research and Development of Radiation Protection Plexiglass[J]. Journal of South-Central University for Nationalities(Natural Science Edition), 2004(04): 30-32.

(6) Kissinger H E. Reaction kinetics in differential thermal analysis[J]. Analytical chemistry, 29(11): 1702-1706, 1957.

(7) Zhao H, Gao J, Li Y, et al. Curing kinetics and thermal property characterization of bisphenol-F epoxy resin and MeTHPA system[J]. Journal of thermal analysis and calorimetry, 74(1): 227-236, 2003.

(8) Wen S, Zhou Y, Yao L, et al. In situ self-polymerization of unsaturated metal methacrylate and its dispersion mechanism in rubber-based composites[J]. Thermochimica Acta, 571: 15-20, 2013.

(9) Collins EA, Bares J, Billmeyer Jr FW. Experiments in polymer science. New York: Wiley-Interscience. p. 8,1973. (10) Lin H R. Solution polymerization of acrylamide using potassium persulfate as an initiator: kinetic studies, temperature and $\mathrm{pH}$ dependence[J]. European Polymer Journal, 37(7): 1507-1510, 2001.

(11) Behari K, Taunk K, Das R. Polymerization of acrylamide and methacrylamide initiated by a potassium peroxydiphosphate/Mn (II) system[J]. Polymer international, 46(2): 126-130, 1998.

(12) Cowie JMG. In: Allen G, Bevington JC, editors.

Comprehensive polymer science, part 1, vol. 3. Oxford:

Pergamon. p. 1,1989

(13) Fineman M, Ross S D. Linear method for determining monomer reactivity ratios in copolymerization[J]. Journal of Polymer Science, 5(2): 259-262, 1950. 